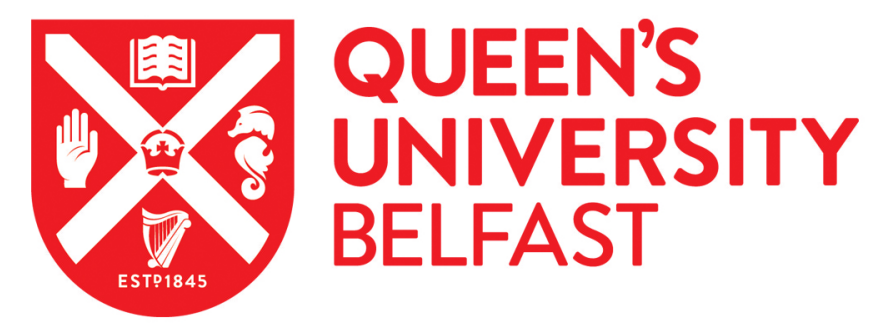

\title{
Protocol: An efficacy randomized controlled trial of a spelling program in primary schools
}

Cockerill, M., Thurston, A., \& Taylor, A. (2019). Protocol: An efficacy randomized controlled trial of a spelling program in primary schools. International Journal of Educational Research, 97, 131-138.

https://doi.org/10.1016/j.ijer.2019.07.001

Published in:

International Journal of Educational Research

Document Version:

Peer reviewed version

Queen's University Belfast - Research Portal:

Link to publication record in Queen's University Belfast Research Portal

\section{Publisher rights}

Copyright 2019 Elsevier Ltd

This manuscript is distributed under a Creative Commons Attribution-NonCommercial-NoDerivs License

(https://creativecommons.org/licenses/by-nc-nd/4.0/), which permits distribution and reproduction for non-commercial purposes, provided the author and source are cited.

\section{General rights}

Copyright for the publications made accessible via the Queen's University Belfast Research Portal is retained by the author(s) and / or other copyright owners and it is a condition of accessing these publications that users recognise and abide by the legal requirements associated with these rights.

Take down policy

The Research Portal is Queen's institutional repository that provides access to Queen's research output. Every effort has been made to ensure that content in the Research Portal does not infringe any person's rights, or applicable UK laws. If you discover content in the Research Portal that you believe breaches copyright or violates any law, please contact openaccess@qub.ac.uk. 


\title{
Protocol: An efficacy randomized controlled trial of a Spelling program in
} primary schools

\begin{abstract}
This paper presents the research protocol for an efficacy randomized controlled trial of a spelling program in primary schools. The program is a workforce development program that supports Teachers and Teaching Assistants develop and deliver targeted spelling instruction to children aged 8-10. The protocol outlines a research design to assess whether the program delivered over 10-12 weeks improves spelling, writing and reading-comprehension outcomes, in a sample of 120 children from 10 schools in two English districts with high socio-economic disadvantage. The outcome measures include spelling and reading standardized tests, and spelling/writing diagnostic test. A process evaluation will measure fidelity and potential for scale-up.
\end{abstract}

\section{Key Words}

Spelling; Comprehension; Primary School; Teacher Training; Literacy; RCT

\section{Background}

The consequences of poor spelling are apparent in reading and in writing. In 2013, to address poor literacy outcomes in England at age 11, the UK government introduced a standardized spelling, punctuation and grammar test for primary school age children (Department for Education, 2013). This test was to accompany the already existing standardized reading test completed by pupils aged 11 .

This move to implement spelling tests and by consequence spelling instruction in primary education is congruent with recommendations from research (Foorman \& Petscher, 2010). The literature identifies spelling ability as an independent predictor of both fluency and reading comprehension, above and beyond reading fluency (Nunes, Bryant \& Barros, 2012; Little \& Hart, 2016).

As reading is recognized as a foundational skill for learning (Snowling \& Hulme, 2012), and beyond the UK situation, there is also international interest in improving reading comprehension levels (Organization for Economic Cooperation and Development, 2017; The United Nations Educational, Scientific and Cultural Organization, 2009), encouraging spelling instruction in classrooms is a reasonable strategy for improvement.

With respect to writing, research suggests that lack of knowledge of a word's spelling leads to avoidance of words and, hence, less lexical diversity (Moats, Foorman \& Taylor, 2006). Although fast and accurate spelling is a key component of writing fluency, there is limited high-quality evidence about how to teach spelling (DFE, 2012; EEF 2017). 
The following protocol describes a Level 3 efficacy randomized controlled trial (Early Intervention Foundation, 2018) study aimed at evaluating the impact of a new spelling program on pupils' attainment in spelling, writing and reading comprehension on a targeted basis. This study has been funded by the Education Endowment Foundation North East Primary Literacy Campaign in the UK, as part of the Transforming Tees Advocacy program.

\section{The Intervention}

The Fischer Family Trust (FFT) spelling program was developed in 2018. The intervention is delivered by practicing Teachers/Teaching Assistants in mainstream UK settings for pupils aged 8 to 10 years, and workforce development is an essential part of the program. All Teachers/Teaching Assistants involved in delivering the program receive one and half days' off-site training from FFT, who also provide on-site advisory support during delivery of the program (half day in schools). The training covers the knowledge, skills and understanding that practitioners need to deliver the FFT spelling program in a targeted format. The training covers an understanding of the nature of spelling and a multi-strategy approach key to spelling instruction; learning activities, and instructional components such as diagnosing student's spelling issues, how to conduct spelling sessions and associated issues such as the use of planning and recording sheets.

Spelling instruction to the identified small group of pupils, selected on the basis that they are 'good writers but poor spellers', is teacher-led. The task is to encourage spellers to draw on three sources of information (sound, meaning and visual) to emphasise a balanced approach to learning spelling, starting from the specific difficulties vulnerable spellers demonstrate. This approach is modelled by the teacher. The participants are pupils in mixed-ability Year 4 and 5 classes (8 to 10 years).

Teachers and Teaching Assistants involved in this targeted spelling program deliver sessions of 15-20 minutes in length to small groups of approximately 3 pupils aged 8 to 10 years (Year 4 and Year 5 in primary schools in England) who have been identified as being 'good writers and poor spellers'. The frequency in this targeted program is 2-3 times a week for approximately 12 weeks over one academic term.

The program is structured as follows over the 10-12-weeks of delivery:

- Weeks 1 to 3/4: Phase 1 - Individual spelling errors focus

- Weeks 3/4 to 6/8: Phase 2 - Expanding from specific word errors to word sets which follow the same sound or meaning patterns

- Weeks 6/8 to 9/12: Phase 3 - Focusing on most common areas of weakness (as identified by the miscue)

- Week 12: Preparation for returning to classwork, pre or re-teaching of classbased objectives.

The FFT spelling program comprises:

a) A diagnostic analysis tool of pupil spelling skills to identify instructional requirement and progress; 
b) A set of strategies (sound, meaning, visual) - used to develop a balanced approach to spelling instruction and learning modelled during training and included in a teacher manual;

c) Materials -a resource box including magnetic letters, phoneme frames, game boards and activities including specific approaches to teaching and learning spellings which constitute the consistent practices to be embedded when learning new spellings (involving use of phonic, meaning and visual clues), and a spelling journal for pupils to capture development.

The spelling program is summarised in Table 1. The treatment group pupils receive the intervention, while the control group pupils continue with business as usual, comprising of their normal and specific literacy instruction practices for pupils aged 8 to 10 years.

Table 1: Spelling Program TIDieR checklist (Hoffman, Glasziou, Boutron, Milne, Perera, Moher, Altman, Barbour, Macdonald, Johnston, Lamb, Dixon-Wodds, McCulloch, Wyatt, Chan, \& Michie, 2014).

\begin{tabular}{|c|c|}
\hline ITEM No. & Item \\
\hline \multicolumn{2}{|l|}{ Brief Name } \\
\hline a & Spelling program (Targeted intervention) \\
\hline \multicolumn{2}{|l|}{ Why } \\
\hline b & $\begin{array}{l}\text { Training program for teachers aimed at improving spelling ability of pupils } \\
\text { aged } 8 \text { to } 10 \text { years }\end{array}$ \\
\hline \multicolumn{2}{|r|}{ gen } \\
\hline c & $\begin{array}{l}\text { Materials: A teacher training program delivered by the Fischer Family Trust } \\
\text { Literacy, which includes external school training (for teachers and teaching } \\
\text { assistants) interspersed with internal follow up support/training. } \\
\text { Resources: including teacher manual, diagnostic tool, and teaching } \\
\text { resource box. }\end{array}$ \\
\hline$d$ & $\begin{array}{l}\text { Procedures: External school training for the spelling program teacher lead, } \\
\text { and designated teaching assistants. Internal follow up training/support } \\
\text { session have overarching themes of spelling teaching using a diagnostic } \\
\text { tool and balanced instructional approach including three strategies: sound, } \\
\text { meaning and visual elements. }\end{array}$ \\
\hline \multicolumn{2}{|l|}{ Who Provided } \\
\hline e & $\begin{array}{l}\text { Spelling trainer provides teacher and teaching assistant internal and } \\
\text { external training. Teachers and teaching assistants provide spelling } \\
\text { diagnostic and instructional activities to pupils based on their training }\end{array}$ \\
\hline \multicolumn{2}{|r|}{ 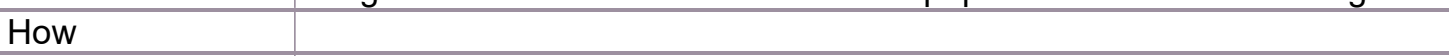 } \\
\hline f & Initial training sessions provided to groups of teachers \\
\hline \multicolumn{2}{|l|}{ Where } \\
\hline g & $\begin{array}{l}\text { External training provided out of school setting. Internal training provided } \\
\text { in school setting including classroom. }\end{array}$ \\
\hline \multicolumn{2}{|l|}{$\begin{array}{l}\text { When and how } \\
\text { much }\end{array}$} \\
\hline $\mathrm{h}$ & $\begin{array}{l}\text { There are two external training sessions and one internal follow up } \\
\text { sessions over the } 12 \text { week period. Teachers are utilizing their training over } \\
\text { the course of the program. }\end{array}$ \\
\hline \multicolumn{2}{|l|}{ Tailoring } \\
\hline i & $\begin{array}{l}\text { The program logic model was not changed during the research and is } \\
\text { included in Figure } 1 .\end{array}$ \\
\hline
\end{tabular}




\begin{tabular}{|l|l|}
\hline $\mathbf{j}$ & No program modifications are being made during the trial. \\
\hline How well & Planned: This will be assessed through the research process evaluation \\
\hline $\mathbf{k}$ & $\begin{array}{l}\text { Actual: This will be assessed through the program pragmatic Randomized } \\
\text { Controlled Trial evaluation. }\end{array}$ \\
\hline $\mathrm{I}$
\end{tabular}

\section{Program Theory of Change (ToC)}

The logic model (Figure 1) describes the program components (Inputs, outputs, outcomes), including the theory of change, and how implementation factors relate to program outcomes. 
Figure 1: Spelling program Logic Model

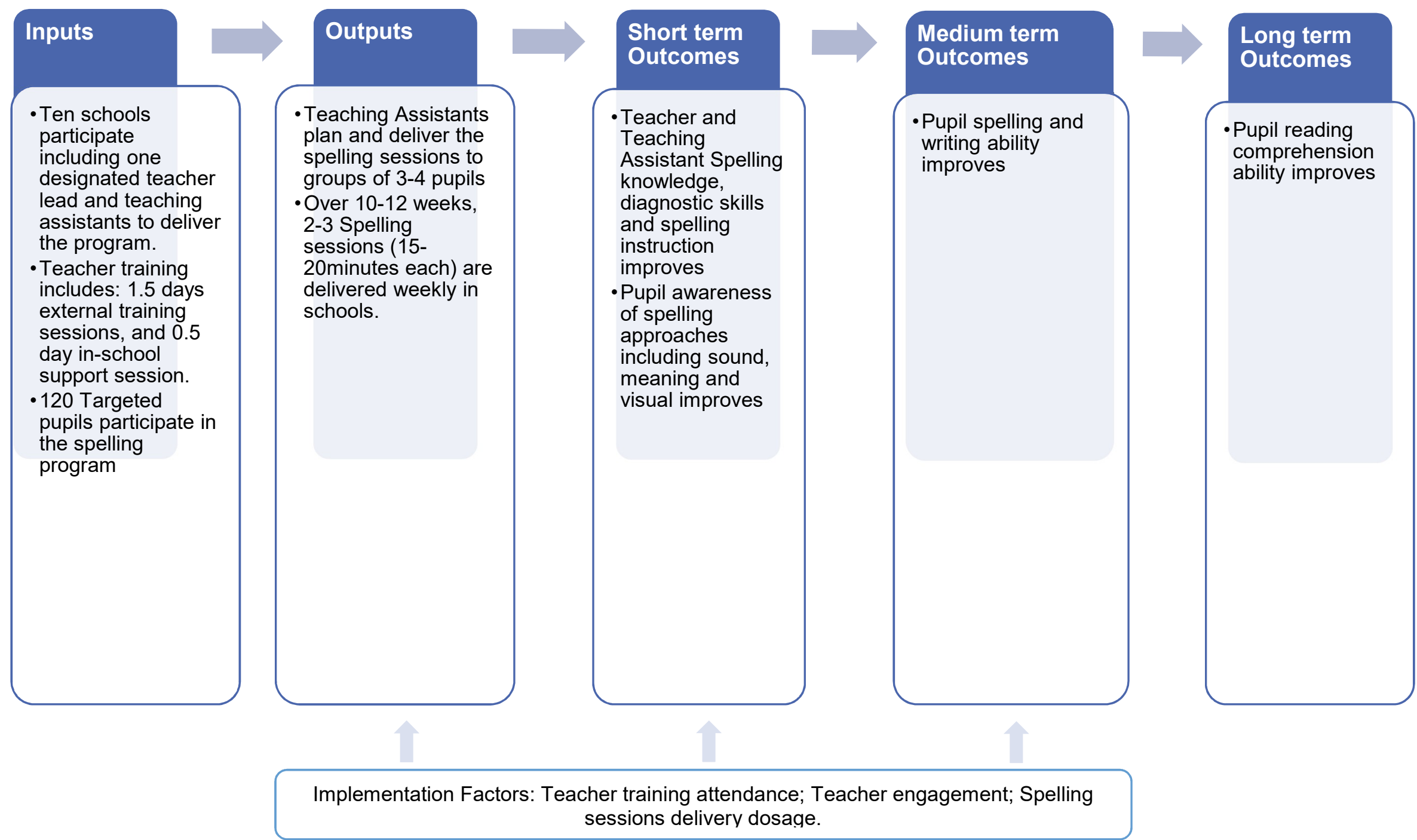




\subsection{Underpinning Theory of Intervention}

The underpinning Theory of Intervention is as follows. As shown in logic model (Figure 1), the overall aim of the spelling program is to increase the spelling ability of children, resulting in improved writing and reading comprehension. In order to achieve these outcomes teacher training is necessary to improve teacher knowledge and change professional practice of spelling instruction, and pupils need to be exposed to regular spaced instruction using a multistrategy spelling approach (sound, meaning and visual).

It is accepted that there is limited high-quality evidence about how to teach spelling (DFE, 2012; EEF 2017). The spelling program therefore seeks to address this by first improving teachers' awareness of spelling strategies and pedagogical methodologies and tools to implement in the classroom, based on evidence of effective practice. This aim is congruent with research which suggests that pupil spelling abilities can be enhanced through spelling teaching instruction, resulting in writing fluency (Bhattacharya \& Ehri, 2004) and improved reading comprehension (Foorman \& Petscher, 2010; Nunes et al, 2012).

One of the key elements of the spelling intervention is high quality professional development based on evidence-informed theory (Coe et al., 2014). In this case this includes distributed learning, scaffolded learning, and learning using a multi-strategy approach to spelling (sound, meaning, visual). The training for the spelling program is delivered through external training days where groups of teachers come together from different schools to learn together, combined with in-school support of teachers by program trainers. Teachers are trained on both how to deliver the program, and how to identify children who may have poor spelling using a diagnostic spelling tool which includes three elements: sound, meaning and visual approaches. This tool is adapted from Peters and Smith (1993) and O'Sullivan and Thomas (2007), although these include phonetic and visual approaches only in their diagnostic tool which undervalues the importance of meaning in spelling instruction and diagnosis.

During spelling instruction teachers focus on developing three strategies with children: visual, sound and meaning. Training and materials are based on the following underpinning theories and evidence:

With respect to reading, incomplete orthographic representations impede decoding (Foorman \& Francis, 1994). In addition to reading fluency skills, spelling as a skill is significantly related to success in reading comprehension (Ehri, 2000; Hook \& Jones, 2002; Pikulski \& Chard, 2005; Nunes, Bryant, \& Barros, 2012), and spelling instruction must be a part of a teacher's goal to engage students in reading for understanding (Foorman \& Petscher, 2010). With respect to writing, fast and accurate spelling is a key component of writing fluency (Bhattacharya \& Ehri, 2004), and lack of knowledge of a word's spelling leads to avoidance of words and, hence, less lexical diversity (Moats, Foorman, \& Taylor, 2006).

The spelling program is underpinned by the theories of distributed learning, scaffolded learning in small groups, and a multi-strategy approach to teaching spelling which includes, sound, meaning and visual approaches. 
1) Distributed learning or spaced learning which stem from the psychology and neuroscience literature, where two or more study periods are separated in time by an inter-study interval, has been hypothesized to have a greater impact on learning outcomes than block learning (Rea \& Modigliani, 1985, 1987; Seabrook, Gordon, Brown \& Solity, 2005; Solity \& Vousden, 2009).

2) Vygotsky's theory (1978) of learning within the 'zone of proximal development' which requires mediation and carefully directed support, also underpins this spelling program, which includes structured delivery in small groups of three children working together with teacher support to make this scaffolded learning possible. This approach is in line with research which suggests scaffolding is effective (Van de Pol, Volman \& Beishuizen, 2010).

3) Research suggests that spelling involves representing sounds in words, representing the words themselves and the links between words (Apel \& Masterson, 2001; Treiman, 2017). Difficulties with morphology are said to affect the spelling skills of children, impeding the ability to build an orthographic (spelling) lexicon and to represent morphemes in written language (Nelly, Broc, Olive \& Dockrell, 2018). Statistical-learning theories of spelling development propose that young children make use of multiple regularities in the orthography, including morphology (Deacon \& Kirby, 2004; Pacton \& Deacon, 2008; Treiman, 2017). The Lexical Quality Hypothesis suggests that variations in orthographic and phonological decoding contribute to variations among word reading and comprehension skills (Perfetti, 1985; Perfetti \& Hart, 2002). When tested, spelling is found to be a key predictor of reading comprehension, outside of the more commonly studied phonological decoding predictors (Little \& Hart, 2016).

A multi-strategy approach to spelling development which includes practicing phonological, morphological and visual awareness is hypothesized to improve spelling ability and to have an impact on both writing and reading comprehension outcomes. In addition to fluency skills, spelling as a skill is significantly related to success in reading (Ehri, 2000; Hook \& Jones, 2002; Pikulski \& Chard, 2005). It is hypothesized therefore that if children improve their morphological awareness in spelling, they will take advantage of the meaningfulness of morphemes for reading comprehension (Nunes et al., 2012). Nunes et al., (2012) demonstrate that the use of both grapho-phonic units and the use of morphemes in spelling are necessary in spelling instruction, and that a multi-strategy approach to spelling is predictive of improvements in reading comprehension.

The impact of the multi-strategy approach of the spelling program on spelling, writing and reading comprehension abilities of pupils will be investigated using a spelling diagnostic measure and an online spelling and reading comprehension test measure respectively.

\subsection{Theory of Change}

Figure 1 also illustrates the ToC. It is proposed that by providing a structured spelling program and appropriate training to teachers and teaching assistants, 
that the processes underpinning the teaching of spelling can be changed. This assumes that the training will impact on the professional action of teachers and teaching assistants, resulting in use of alternative pedagogies. As a result, it is projected that pupil use of sound, meaning and visual approaches to improve their spelling skills and spelling knowledge will lead to improved spelling. This in turn will lead to improved writing and finally to improved reading.

Teacher surveys and attendance at training, in addition to spelling instruction dosage will be analyzed as implementation factors/mediators for outcome change.

\section{Research Plan}

Research questions

The spelling program study will be a Level 3 efficacy trial (randomized at the individual pupil level, using block randomization to ensure even numbers of intervention and control pupils in each arm of the trial within each of the 10 schools) complemented by a process evaluation. The study will primarily look at the effect of the spelling program on the spelling ability, writing ability and reading ability of children in primary schools. Pre and post-test measures of 120 children in 10 schools will assess the efficacy of the spelling program in optimal conditions on a small scale.

The study will address the following questions:

a) Can the program be delivered in primary schools?

b) What is the impact of the spelling program at post-test on:

- Children's spelling ability

- Children's writing ability

- Children's reading ability?

c) Does the impact of the program differ significantly according to variations in implementation fidelity? (Process evaluation)

d) Is the program scalable?

Answers to the above questions will inform decisions as to whether the program is ready to be scaled to an effectiveness trial.

\section{Design summary of the randomized controlled trial (RCT) and process evaluation}

5.1 Logic Model: A logic model has been developed for the spelling program intervention (Fig. 1). The logic model will help guide the process evaluation and enable us to interpret the findings of the RCT. The SPIRIT guidelines have been consulted to help structure the protocol for this trial (SPIRIT, 2015).

5.2 RCT Evaluation: The main outcomes will be evaluated using ANCOVA analysis. The RCT will test for changes in both children's spelling, writing and 
reading abilities. Any changes in the intervention group receiving the 10-12week spelling program will be measured against the control group who do not receive the treatment. It is calculated that the sample is large enough to detect a significant Effect Size of 0.2 , with $\mathrm{p}>0.05$, and $80 \%$ power (Soper, 2019). Results will also be presented as Effect Sizes and Cohen's $d$ will be calculated for each of the main outcome measures.

5.3 Process evaluation: A process evaluation will supplement the RCT to measure the fidelity to implementation for the program. Guided by the MRC Framework (Moore, Audrey, Barker, Bond, Bonell, Hardeman, Moore, O'Cathcain, Tinati, Wight \& Bair, 2015) the process evaluation will seek to assess whether the spelling training was attended, teacher engagement, and dosage of implementation. To help assess this, the trainer will provide naturally occurring training attendance data, and teacher leads and teaching assistants will complete a post-program perception survey, including questions about learning for the control group during the program.

\section{Assessment procedures}

All children in both intervention and control groups will be tested before and after the intervention. Schools will be provided by the trainers with guidance to select the 12 children from years 4 and 5 who are good writers and poor spellers.

\subsection{Pre-test measures}

The selected children, 12 from years 4 and 5 , will be tested prior to teacher training and program intervention.

- Spelling pre-test: All the children in the study $(n=120)$ will complete a standardized spelling test, the New Group Spelling Test, the digital version, from GL-Assessment. This is an adaptive test which has high reliability (Alpha values 0.95) (GL-Assessment, 2018). All children will be tested in exam conditions by schools prior to teacher training and program intervention. These will assess children's spelling ability, including overall spelling and number of spelling words attempted.

- Spelling diagnostic pre-test: Two recent pieces of writing from the selected children will be used to undertake the diagnostic test prior to teacher training and program intervention.

- Writing measure: Two piece of free writing undertaken by all children will be used to undertake analysis of fluency, complexity and accuracy of free writing in English.

\subsection{Post-test measures}

These will be repeated with all treatment and control children 12 weeks after the program has started. This will include the following tests:

- Spelling post-test: All participating children from each school will complete the online standardized spelling test, the New Group Spelling Test from GL-Assessment. All children will be tested in exam conditions by schools 
- Spelling diagnostic post-test: Two recent pieces of writing from the selected children will be selected by the school and sent to the FFT Literacy trainer to undertake the diagnostic test after the end of the program delivery.

- Writing measure: Pupils will be asked to undertake a free writing task. Free writing will be assessed using the formulae described by WolfeQuintero, Inagaki, and Kim (1998). They described measures for analysing the fluency, accuracy and complexity of free writing in modern languages. The formulae they described for fluency was number of words per sentence, for accuracy was number of mistakes per sentence and for complexity was number of clauses per sentence (or grammatical complexity). All analysis will be undertaken by the same researcher to ensure internal consistency between analysis of free writing.

- Reading post-test: The selected children from each school will complete an online standardized reading test, the New Group Reading Test (digital version) from GL-Assessment. This is an adaptive test which has high reliability (Alpha values 0.9) (GL-Assessment, 2018). All children will be tested in exam conditions by schools prior to teacher training and program intervention. These will assess children's reading ability, including sentence completion and reading comprehension.

\subsection{Dosage record:}

A 12-week teacher implementation session delivery plan (including 2-3 weekly sessions of 15-20 minutes each) will be used by teachers to record weekly delivery data and will be collected at post-test to help measure the program's implementation fidelity.

\subsection{Teacher questionnaire at post-test}

The teachers and teaching assistants will be asked to fill in a questionnaire at post-test for their feedback regarding the spelling program and the implementation process. All questionnaires will be completed online using Lime Survey. The teacher questionnaire will consist of 19 questions to include 11 questions measured on a 4-point scale ranging from 'strongly agree' to 'strongly disagree'. In addition, the questionnaire will include 5 open questions and three closed questions with menu of options about session delivery.

6.5 Training delivery naturally occurring data: training attendance. Training attendance records will be collected by FFT Literacy program trainers.

Instruments and measures are summarized in Table 3.

Table 3: Measurement tools

\begin{tabular}{|l|l|l|l|}
\hline Outcome & Instrument & Completed by & Alpha values \\
\hline Overall spelling & $\begin{array}{l}\text { New Group Spelling } \\
\text { Test }\end{array}$ & Pupil & $\begin{array}{l}0.95(\mathrm{GL} \\
\text { Assessment, } \\
2018)\end{array}$ \\
\hline $\begin{array}{l}\text { Number of words } \\
\text { attempted }\end{array}$ & $\begin{array}{l}\text { New Group Spelling } \\
\text { Test - number of }\end{array}$ & Pupil & $\begin{array}{l}0.95(\mathrm{GL} \\
\text { Assessment, } \\
2018)\end{array}$ \\
\hline
\end{tabular}




\begin{tabular}{|c|c|c|c|}
\hline & $\begin{array}{l}\text { words attempted } \\
\text { subtest }\end{array}$ & & \\
\hline Writing & Diagnostic test & $\begin{array}{l}\text { Trainer using } 2 \text { pieces of } \\
\text { pupil writing. }\end{array}$ & $\mathrm{n} / \mathrm{a}$ \\
\hline Writing & $\begin{array}{l}\text { Analysis of free writing } \\
\text { using independently } \\
\text { developed formulae } \\
\text { for analysis of fluency, } \\
\text { accuracy and } \\
\text { complexity. }\end{array}$ & $\begin{array}{l}\text { Pupil and analysed by } \\
\text { Researcher }\end{array}$ & $\mathrm{n} / \mathrm{a}$ \\
\hline $\begin{array}{l}\text { Reading } \\
\text { Comprehension }\end{array}$ & $\begin{array}{l}\text { New Group Reading } \\
\text { Test - Passage } \\
\text { Comprehension } \\
\text { subtest }\end{array}$ & Pupil & $\begin{array}{l}0.9 \text { (GL } \\
\text { Assessment, } \\
\text { 2018) }\end{array}$ \\
\hline Overall reading & $\begin{array}{l}\text { New Group Reading } \\
\text { Test }\end{array}$ & Pupil & $\begin{array}{l}0.9 \text { (GL } \\
\text { Assessment, } \\
\text { 2018) }\end{array}$ \\
\hline Reading accuracy & $\begin{array}{l}\text { New Group Reading } \\
\text { Test - Sentence } \\
\text { completion subtest }\end{array}$ & Pupil & $\begin{array}{l}0.9 \text { (GL } \\
\text { Assessment, } \\
\text { 2018) }\end{array}$ \\
\hline \multicolumn{4}{|l|}{$\begin{array}{l}\text { Implementation } \\
\text { factors }\end{array}$} \\
\hline Dosage & $\begin{array}{l}\text { 10-12-week } \\
\text { implementation ( } 1 / 2 \\
\text { hour to } 1 \text { hour weekly) }\end{array}$ & Teacher & $\mathrm{n} / \mathrm{a}$ \\
\hline $\begin{array}{l}\text { Teacher } \\
\text { engagement }\end{array}$ & Training attendance & Trainer & $\mathrm{n} / \mathrm{a}$ \\
\hline $\begin{array}{l}\text { Teacher } \\
\text { engagement }\end{array}$ & Teacher survey & Teacher & $\mathrm{n} / \mathrm{a}$ \\
\hline
\end{tabular}

\section{Sample}

120 pupils in Years 4 and 5 (pupils aged 8 to 10 years), from 10 schools in the North East of England will be recruited to the trial. The trial recruited 6 students from each class ( 3 to act as intervention and 3 to act as control), 12 from each school. Pupils were eligible to take part in this trial if the school selected them as being good writers but poor spellers, using the guidance provided to them.

\section{Randomization}

Pupils will be individually randomized to condition. This will be undertaken by listing the students alphabetically within their year group and school. A random number generator (Random Number Generator for iPhone version 5.0 by Nicolas Dean) will be used to generate a whole number between 0 (control) and 1 (spelling intervention). Once the first student from a class was assigned to condition the other 5 students were randomized sequentially to condition. This will ensure even numbers of intervention and control pupils in each arm of the trial.

\section{Sample size calculation and analysis}

The primary outcome will be to establish Effect Sizes of the intervention. In line with MRC exploratory trials, Effects Sizes and 95\% confidence intervals will be 
presented.

10. Personnel

- Professor Allen Thurston, Queen's University Belfast

- Dr Maria Cockerill, Queens University Belfast

- Andy Taylor, Fischer Family Trust Literacy (program trainer).

\section{Timescales}

The planned timescale for the research is from September 2018 until December 2018. Table 2 below outlines a summary of the key milestones.

Table 2. Gannt Chart of timescales

\begin{tabular}{|c|c|c|c|c|c|c|c|c|c|c|}
\hline Activities & Jun18 & Jul18 & Sep18 & Oct18 & Nov18 & Dec18 & Jan19 & Feb19 & Mar19 & Apr19 \\
\hline $\begin{array}{l}\text { Develop } \\
\text { logic model }\end{array}$ & & & & & & & & & & \\
\hline $\begin{array}{l}\text { Recruit } \\
\text { schools }\end{array}$ & & & & & & & & & & \\
\hline $\begin{array}{l}\text { Diagnostic } \\
\text { pre-test and } \\
\text { writing } \\
\text { measure }\end{array}$ & & & & & & & & & & \\
\hline $\begin{array}{l}\text { Spelling } \\
\text { pretest data }\end{array}$ & & & & & & & & & & \\
\hline $\begin{array}{l}\text { Develop } \\
\text { survey } \\
\text { measures }\end{array}$ & & & & & & & & & & \\
\hline $\begin{array}{l}\text { Training day } \\
1(1.0)\end{array}$ & & & & & & & & & & \\
\hline $\begin{array}{l}\text { Program } \\
\text { delivery in } \\
\text { schools }\end{array}$ & & & & & & & & & & \\
\hline $\begin{array}{l}\text { Training day } \\
2(0.5)\end{array}$ & & & & & & & & & & \\
\hline $\begin{array}{l}\text { In-school } \\
\text { support visit }\end{array}$ & & & & & & & & & & \\
\hline $\begin{array}{l}\text { Spelling pos } \\
\text { test }\end{array}$ & & & & & & & & & & \\
\hline $\begin{array}{l}\text { Diagnostic } \\
\text { post test anc } \\
\text { writing } \\
\text { measure }\end{array}$ & & & & & & & & & & \\
\hline $\begin{array}{l}\text { Reading } \\
\text { post test }\end{array}$ & & & & & & & & & & \\
\hline $\begin{array}{l}\text { Teacher } \\
\text { survey }\end{array}$ & & & & & & & & & & \\
\hline $\begin{array}{l}\text { Session } \\
\text { delivery data }\end{array}$ & & & & & & & & & & \\
\hline $\begin{array}{l}\text { Analysis of } \\
\text { data }\end{array}$ & & & & & & & & & & \\
\hline $\begin{array}{l}\text { Write-up to } \\
\text { include } \\
\text { process } \\
\text { evaluation }\end{array}$ & & & & & & & & & & \\
\hline Final report & & & & & & & & & & \\
\hline
\end{tabular}

12. Cost 
The cost of implementing the program will include resources and personnel time spent on delivering the program with follow up support. The cost of the spelling program implementation will be estimated per pupil over a one-year period and will include: Teacher training 1.5 days (external sessions); teacher in-school support session 0.5 days; teacher manual, spelling instruction resource box for session delivery.

\section{Ethics}

The trial was approved through two ethics procedures. The intervention of the trial and testing was approved by the Headteachers who took part in the trial. The subsequent matching, combining and analysis of data was approved by the School of Social Sciences, Education and Social Work Ethics Committee from Queen's University Belfast.

\section{References}

Apel, K., and Masterson, J.J. (2001) Theory-Guided Spelling Assessment and Intervention: A Case Study. Language, Speech, and Hearing Services in Schools Clinical Forum1 Jul 2001. Doi.org/10.1044/0161-146

Bhattacharya, A., and Ehri, L. C. (2004). Graphosyllabic Analysis Helps Adolescent Struggling Readers Read and Spell Words. Journal of Learning Disabilities, 37(4), 331 348. doi.org/10.1177/00222194040370040501

Breadmore, H.L., and Deacon, S.H. (2019) Morphological Processing Before and During Children's Spelling, Scientific Studies of Reading, 23:2, 178191, DOI: 10.1080/10888438.2018.1499745. Taylor and Francis online.

Coe, R., Aloisi, C., Higgins, S., Elliot Major, L. (2014) What makes great teaching? Review of the underpinning research.

https://www.suttontrust.com/wp-content/uploads/2014/10/What-Makes-GreatTeaching-REPORT.pdf

Deacon, S. H., \& Kirby, J. R. (2004). Morphological awareness: Just "more phonological"? The roles of morphological and phonological awareness in reading development. Applied Psycholinguistics, 25, 223-238. doi: $10.1017 /$ S0142716404001110

Department for Education (2012) 'What is the research evidence on writing?', Research report DFE-RR238, London: Department for Education.

https://assets.publishing.service.gov.uk/government/uploads/system/uploads/ attachment data/file/183399/DFE-RR238.pdf

Department for Education (2013) Press Release: New grammar, punctuation and spelling test will raise children's literacy standards. Retrieved from: 
https://www.gov.uk/government/news/new-grammar-punctuation-and-spellingtest-will-raise-childrens-literacy-standards (1st February, 2019).

Early Intervention Foundation (2018). EIF Evidence Standards. Retrieved from: http://www.eif.org.uk/eif-evidence-standards/ (1 ${ }^{\text {st }}$ February 2019).

Education Endowment Foundation (2017) North East Literacy Campaign: Improving Literacy in Key Stage 2.

https://educationendowmentfoundation.org.uk/tools/guidance-reports/literacy$\underline{\mathrm{ks}-2}$

Ehri, L.C. (2000). Learning to read and learning to spell: Two sides of a coin. Topics in Language Disorders, 20(3), 19-36.

Foorman, B.R., and Petscher, Y. (2010). Development of spelling and differential relations to text reading in grades 3-12. Assessment for Effective Intervention, 36(1), 7-20.

Foorman, B.R., Petscher, Y., and Bishop, M.D. (2012). The incremental variance of morphological knowledge to reading comprehension in grades $3-$ 10 beyond prior reading comprehension, spelling, and text reading efficiency. Learning and Individual Differences, 22(6), 792-798.

Foorman, B.R. and Francis, D.J. (1994) Exploring connections among reading, spelling, and phonemic segmentation during first grade. Reading and Writing. 6(1). pp65-91. doi.org/10.1007/BF01027278. Springer Link.

Hoffmann, T., Glasziou. P., Boutron I, Milne R, Perera R, Moher D, Altman D, Barbour V, Macdonald H, Johnston M, Lamb S, Dixon-Woods M, McCulloch P, Wyatt J, Chan A, and Michie S. (2014) Better reporting of interventions: template for intervention description and replication (TIDieR) checklist and guide. BMJ. 348:g1687. Retrieved from:

http://www.bmj.com/content/348/bmj.g1687 (1st February, 2019).

Hook, P.E., and Jones, S.D. (2002). The importance of automaticity and fluency for efficient reading comprehension. Perspectives, 28(1), 9-14.

Kohnen, S., Nickels, L., and Castles, A., (2009) Assessing spelling skills and strategies: A critique of available resources, Australian Journal of Learning Difficulties, 14:1, 113-150, DOI: 10.1080/19404150902783450

Little, C.W., and Hart, S.A. (2016) Examining the genetic and environmental associations among spelling, reading fluency, reading comprehension and a high stakes reading test in a combined sample of third and fourth grade students. Learning and Individual Differences 45 (2016) 25-32. Elsevier.

Moats, L.C., Foorman, B.R., and Taylor, W.P. (2006) How quality of writing instruction impacts high-risk fourth graders writing. Reading and Writing: An Interdisciplinary Journal, 19, 363-391. 
Moore, G. F., Audrey, S., Barker, M., Bond, L., Bonell, C., Hardeman, W., Moore, L., O'Cathain, A., Tinati, T., Wight, D., and Baird, J. (2015). Process evaluation of complex interventions: Medical Research Council guidance. BMJ, 350, 1258. doi: https://doi.org/10.1136/bmj.h1258

Nelly, J., Broc, L., Olive, T., and Dockrell, J. (2018). Spelling Performance In Children With Developmental Language. Scientific Studies of Reading, Vol23(2). Taylor and Francis.

Nunes, T., Bryant, P., and Barros, R. (2012). The Development of Word Recognition and Its Significance for Comprehension and Fluency. Journal of Educational Psychology. Advance online publication. doi: 10.1037/a0027412

Organization for Economic Co-operation and Development (2017), PISA 2015 Assessment and Analytical Framework: Science, Reading, Mathematic, Financial Literacy and Collaborative Problem Solving, revised edition, PISA, OECD Publishing, Paris.

Pacton, S., and Deacon, S.H. (2008). The timing and mechanisms of children's use of morphological information in spelling: A review of evidence from English and French. Cognitive Development, 23(3), 339-359. Elsevier.

Perfetti, C.A. (1985). Reading Ability. Oxford, England: Oxford University Press.

Perfetti, C.A and Hart, L. (2002) The lexial quality hypothesis, in Precursors of Functional Literacy. Edited by Verhoeve, L,. Elbro, C., \& Pieter, R. Studie in Written Language and Literacy 11. Pp 189-213. John Benjamins Publishing Company.

Pikulski, J.J., and Chard, D.J. (2005). Fluency: Bridge between decoding and reading comprehension. The Reading Teacher, 58, 510-519.

doi:10.1598/RT.58.6.2

Rea, C. P., and Modigliani, V. (1985). The effect of expanded versus massed practice on the retention of multiplication facts and spelling lists. Human Learning, 4, 11-18.

Rea, C. P., and Modigliani, V. (1987). The spacing effect in 4- to 9-year-old children. Memory \& Cognition, 15, 436-443.

Seabrook, R., Gordon, D., Brown, A., and Solity, J. (2005) Distributed and Massed Practice: From Laboratory to Classroom. Applied Cognitive Psychology, Vol 19: pp107-122. Onlinelibrary.wiley.com

Snowling, M. J., and Hulme, C. (2012). Interventions for children's language and literacy difficulties. International Journal of Language and Communication Disorders, 47, 27-34. 
Solity, J. and Vousden, J. (2009) Real books vs reading schemes: a new perspective from instructional psychology, Educational Psychology, 29:4, 469511, DOI: 10.1080/01443410903103657. Taylor and Francis online.

Soper, D. (2019). A-priori sample size calculator for multiple regression.

Retrieved from: https://www. danielsoper.com/statcalc/calculator.aspx?id=1 (31 Jan 2019).

SPIRIT (2015). SPIRIT [ONLINE]. Available at: http://www.spiritstatement.org/spirit-statement/. Retrieved $1^{\text {st }}$ February 2019.

The United Nations Educational, Scientific and Cultural Organization (2009) United Nations Literacy Decade International Strategic Framework for Action. September 2009.

Treiman, R. (2017) Learning to Spell Words: Findings, Theories, and Issues, Scientific Studies of Reading, 21:4, 265-276, DOI: 10.1080/10888438.2017.1296449

Van de Pol, J., Volman, M. \& Beishuizen, J. (2010) Scaffolding in TeacherStudent Interaction: A Decade of Research. Educational Psychology Review, 22, 271-296

Vygotsky L. S. (1978). Mind in society: The development of higher psychological processes. Cambridge M.A.: Harvard University Press.

Wolfe-Quintero, K., Inagaki, S., \& Kim, H. Y. (1998). Second language development in writing: Measures of fluency, accuracy and complexity (Technical Report Number 17). Honolulu, USA: University of Hawaii, Second Language Teaching and Curriculum Centre.

\section{Competing Interests Statement}

The authors have no competing interests to declare. 